\title{
PROPRIEDADE INTELECTUAL: UMA ANÁLISE ACERCA DO PROCESSO DE OBTENÇÃO DE PATENTES NO BRASIL
}

\section{INTELLECTUAL PROPERTY: AN ANALYSIS ABOUT BRAZIL'S PATENT OBTAINING PROCESS}

\author{
Isla Laiane Santos de Oliveira \\ Helder Leonardo de Souza Goes²
}

RECEIVED /RECEBIDO 02/12/2019 FEV 2019

APPROVED/APROVADO 06/12/2019 FEV 2019

PUBLISHED /PUBLICADO 18/12/2019 FEV 2019

Editor Responsável: Carla Caldas

Método de Avaliação: Double Blind Review

E-ISSN: 2316-8080

Prefixo do DOI: 10.16928

RESUMO

O presente artigo tem como objetivo explorar as informações acerca do instituto da propriedade intelectual, buscando contemplar a proteção jurídica garantida a tal propriedade na legislação vigente. De forma a destacar a importância do Direito no que tange o norteamento e regulamentação das patentes, imprimindo normas e leis que auxiliam a proteção dos respectivos inventores e de suas criações. Ademais, trazer o enfoque no processo de obtenção de patentes no Brasil, buscando verificar como é feito tal procedimento, o qual se verifica que caminha de forma mais atrasada em relação a outros países, o que acaba por prejudicar a inovação no Brasil, área importante para o desenvolvimento econômico e científico.

Palavras-chaves: Direito Empresarial. Inovação. Patentes. Propriedade Industrial. Propriedade Intelectual 
This article aims to explore the information about the intellectual property institute, seeking to

Graduanda em Direito da Universidade Tiradentes - UNIT. E-mail: islaoliveira96@gmail.com

2Professor do curso de Direito da Universidade Tiradentes - UNIT. E-mail: helderlsgoes@gmail.com

contemplate the legal protection guaranteed to such assets in current legislation. In order to highlight the importance of the law with regard to patent guidance and regulation, printing of rules and laws that assist in protecting the respective inventors and their creations. In addition, focus on the process of obtaining patents in Brazil, seeking to verify how this procedure is performed, which ultimately falls behind other countries, which ultimately undermines innovation in Brazil, an important area for economic and social development. scientific.

Keywords: Business law. Innovation. Patents. Industrial property. Intellectual property

\section{INTRODUÇÃO}

Ao longo da história da humanidade é possível perceber que a criatividade humana foi o ponto central para o desenvolvimento da sociedade como um todo. A busca por mecanismos que melhorassem a qualidade de vida e solucionassem problemas, proporcionou os grandes avanços que transformaram o mundo.

Assim, com o progresso das inovações advindas da engenhosidade humana e também com a velocidade com a qual as informações passaram a ser difundidas, surgiu a preocupação em proteger essas ideias, de forma que cada indivíduo pudesse colher os frutos de suas criações.

Dessa forma, tem-se no instituto da propriedade intelectual um meio pelo qual o direito protege os inventores, garantindo o bônus das suas obras. Nesse sentido, a lei 9.279196, regula os direitos e obrigações relativos à propriedade industrial garantindo, mediante o devido registro, o privilégio e proteção aos autores sobre suas criações, por meio da sua correspondente patente.

O presente artigo se justifica partindo do ponto primordial de que o sistema de patentes tem a função vital de incentivar a criação e, por conseguinte, trazer desenvolvimento econômico para o país, uma vez que, a capacidade de inovação está diretamente relacionada com o aprimoramento das vantagens competitivas. Dessa forma, tratar sobre inovação é destacar não apenas o necessário estimulo as pesquisas científicas como também os seus inegáveis benefícios trazidos para sociedade. 
PROPRIEDADE INTELECTUAL: UMA ANÁLISE ACERCA DO PROCESSO DE OBTENÇÃO DE PATENTES NO BRASIL

E-ISSN 2316-8080

O cerne do problema de tal cenário encontra-se nas dificuldades enfrentadas pelo Brasil no seu setor de criação, de acordo com dados do Instituto Nacional da Propriedade Industrial (INPI), em seu relatório anual de 2018, o tempo médio de espera entre o pedido e a concessão de patentes no INPI, órgão subordinado ao Ministério da Indústria, Comércio Exterior e Serviços (MDIC), está em torno de dez anos. Enquanto isso, nos principais países do mundo esses prazos giram em torno de três anos.

Tal quadro faz com que o país perca chances de desenvolver novas tecnologias, além de ser um desestímulo para novos inventores. Dessa forma, o presente artigo visa ao passo que apresenta as mais pertinentes informações e dados sobre o tema, trazer um quadro a respeito do panorama das patentes no Brasil, de forma a demostrar seu impacto no desenvolvimento do país como um todo e entender a que se deve esse relativo atraso, compreendendo de forma mais esclarecedora os aspectos que necessitam de aperfeiçoamento.

Para realizar este propósito, o presente artigo encontra-se organizado em três capítulos, sendo que o primeiro visa abordar os principais apontamentos presentes na doutrina e legislação vigente no que concerne a propriedade intelectual, no que tange, principalmente, as patentes, destacando, não apenas, a sua importância para o progresso cientifico e tecnológico do país, como também enfatizando os requisitos necessários para a sua obtenção.

O segundo capítulo, notadamente, visa esmiuçar o sistema de patentes brasileiro, frisando, em síntese, como o órgão responsável por tal instituto, o INPI, realiza as etapas para a obtenção do referido registro, além de apontar os principais mecanismos de proteção aos autores que a legislação brasileira oferece.

Por fim, o terceiro capítulo, apresenta os principais dados estatísticos recentes acerca do tema proposto, que exemplificam a situação atual da inovação no Brasil, apontando não apenas, os avanços dos últimos anos, como também traçando um perfil dos depositantes, para dessa forma, abarcar melhor o atual cenário e os avanços necessários que esse carece.

A metodologia utilizada nesse artigo foi predominantemente o exploratório e a técnica empregada a revisão, não só bibliográfica como também legislativa, tanto constitucional quanto infraconstitucional, além disso, notícias recentes as quais trazem os atuais avanços que o sistema de patentes no Brasil vem alcançado, e também o levantamento de dados levantados em órgãos como o Instituto Nacional da Propriedade Industrial (INPI). 


\section{PONTERAÇÕES A RESPEITO DO INSTITUTO DA PROPRIEDADE INTELECTUAL}

A crescente busca de novos produtos que facilitem a produção industrial e agreguem novos mercados é um desafio que os criadores buscam suprir, dessa forma a proteção que a legislação garante a propriedade industrial permite um amparo aos detentores de tal propriedade frente a possível exploração de terceiros sobre aquilo que the levou tempo e investimento.

O direito possuí função vital, no que tange a propriedade intelectual, pois defini regras que permitem tornar a criação intelectual um bem jurídico, ou seja, um direito pessoal com expressão econômica, ao qual se dá uma unidade como as que possuem os objetos concretos, passível inclusive de cessão (MAMEDE, 2015).

Dessa forma, a chamada propriedade intelectual, surge como um meio para garantir proteção aos inventores, a Organização Mundial da Propriedade Intelectual (OMPI), define a propriedade intelectual como: A soma dos direitos relativos às obras literárias, artísticas e científicas, às
interpretações dos artistas intérpretes e às execuções dos artistas, aos fonogramas e
às emissões de radiodifusão, às invenções em todos os domínios da atividade humana,
às descobertas científicas, aos desenhos e modelos industriais, às marcas industriais,
comerciais e de serviço, bem como às firmas comerciais e denominações comerciais,
à proteção contra a concorrência desleal e todos os outros direitos inentes à atividade
intelectual nos domínios industrial, científico, literário e artístico (BARBOSA, 2003,
p.10).

A Constituição Federal, no seu artigo $5^{\circ}$, que trata dos direitos e deveres individuais e coletivos, estabelece o direito à proteção das criações intelectuais:

XXVII - aos autores pertence o direito exclusivo de utilização, publicação ou reprodução de suas obras, transmissível aos herdeiros pelo tempo que a lei deixar. XXIX - a lei assegurará aos autores de inventos industriais privilégio temporário para utilização, bem como proteção às criações industriais, à propriedade das marcas, os nomes de empresas e a outros signos distintos, tendo em vista o interesse social e o desenvolvimento tecnológico eeconômico do País.

Conforme Teixeira $(2006$, p.1) a propriedade intelectual é "o direito de que qualquer cidadão, empresa ou instituição tem sobre tudo o que resulta de sua inteligência ou criatividade". A propriedade intelectual, tem o papel fundamental de promover o desenvolvimento científico e tecnológico através da concessão de um monopólio, por um tempo determinado, de direitos exclusivos de comercialização de produtos e processos aos seus inventores. Assim, convencionalmente, como já pontuado, a propriedade intelectual pode 
PROPRIEDADE INTELECTUAL: UMA ANÁLISE ACERCA DO PROCESSO DE OBTENÇÃO DE PATENTES NO BRASIL

ser dividida em: propriedade industrial, direitos autorais e outros direitos sobre bens imateriais (MACEDO, 2000).

Os direitos autorais regulamentados e protegidos pela lei 9.610/98, estão compreendidos no campo da literatura e das artes e podem ser expressos em diferentes formas, tais como: palavras, símbolos, música, quadros, objetos tridimensionais, ou através da combinação deles, de forma que as leis que protegem os direitos autorais englobam desde livros, poemas, filmes, desenhos até fotografias e desenhos técnicos (CHAVES e NOGUEIRA, 2008).

Já no que diz respeito à propriedade industrial, esta engloba as marcas e as patentes, assim, tal direito regula as relações referentes às obras utilitárias, ou seja, as de bens materiais de uso empresarial (DURÃES, 2013). De acordo com art. 122 da lei 9.279/96, a marca é o sinal visualmente perceptível que identifica e distingui, direta ou indiretamente, produtos e serviços.

Assim, a marca, tem a importância vital de proporcionar uma afinidade e identificação imediata entre determinado produto ou serviço com o seu consumidor, por outro lado, a patente como define Negrão (2015) é um documento que representa o privilégio de exploração, concedida a duas modalidades de direito que tem sua origem na atividade inventiva do homem: a invenção e o modelo de utilidade, o uso da palavra "concessão" é aplicado pois cabe ao Estado conceder o direito a sua exploração, mediante requerimento ao Instituto Nacional da Propriedade Intelectual (INPI); assim ninguém pode reivindicar para si direito exclusivo de exploração de invenção ou de modelo de utilidade sem que antes tenha obtido tal direito por parte do Estado.

Ainda, conceitua Negrão (2015) que a invenção é um ato humano de criação original, lícito, não compreendido no estado da técnica e suscetível de aplicação industrial. Fazzio Junior (2016) esclarece que para uma invenção ser passível de ser patenteada deve reunir os requisitos da novidade, atividade inventiva e aplicação industrial. Ou seja, uma invenção, é a criação de algo que nunca antes havia sido feito, fruto de um trabalho no sentido de buscar respostas para problemas.

No que diz respeito ao modelo de utilidade, esse não é absolutamente novo, mas sim “(...) uma criação que se faz sobre objeto de uso comum, ou sobre partes de um objeto, a determinar-lhe uma nova forma ou disposição, a implicar melhoria no desempenho de suas funções (melhoria no seu uso) ou na sua fabricação." (MAMEDE, 2015, p. 223). 
Nesse sentido, quando tratar-se de modelo de utilidade, esse diz respeito àquelas criações que melhoram a utilização e desempenho de algo que já existe, de maneira a facilitar o seu uso e dessa forma trazer não só um maior aproveitamento, como também tornar mais célere o seu uso.

\subsection{Requisitos que tornam uma criação patenteável}

Um dos requisitos para ter uma invenção como patenteável é a novidade, ligada ao princípio da originalidade, pois não se pode patentear algo que não é novo. Negrão (2015) conceitua novidade como aquilo que é desconhecido pela comunidade científica, técnica ou industrial.

Assim, será considerado novo tudo aquilo que não foi compreendido pelo estado da técnica, que é definido pela lei 9.279/96, em seu artigo $11 \S 1^{\circ}$ como: "tudo aquilo tornado acessível ao público antes da data de depósito do pedido de patente, por descrição escrita ou oral, por uso ou qualquer outro meio, no Brasil ou no exterior"

Para garantir que o inventor mantivesse seu direito e preserva-se a novidade, quando por causa de apresentação pública ou comunicação científica, sua invenção ou modelo de utilidade tornou-se acessível ao público, ou seja, quando a informação foi obtida por terceiros graças ao próprio inventor, a lei estabelece um período de até 12 meses, anteriores à data do depósito ou da prioridade do pedido de patente, no qual não se entenderá como estado de técnica, garantindo assim o direito ao inventor (NEGÃO, 2015).

É importante ressaltar que “(...) não pode alguém, reconhecendo a novidade e aproveitando-se da inércia do inventor, patentear criação ou modelo de utilidade" (MAMEDE, 2015, p. 223).

Mesmo que haja novidade não há como patentear algo que não é fruto da atividade inventiva, ou seja, que não foi criado. Isso quer dizer que não há atividade inventiva na mera descoberta, dessa forma, a aplicação óbvia ou evidente do estado da técnica constatando algo que já existe, é fato que a invenção deve ser resultado de um trabalho e empenho (MAMEDE, 2015).

Negrão (2015), exemplifica um clássico exemplo de invenção, ou seja, produção original, que a ciência da época não pressupunha sua criação nem tão pouco era consequência óbvia dos conhecimentos científicos que já haviam sido divulgados até aquele momento, e que foi responsável por uma verdadeira revolução, tal invenção diz respeito a lâmpada elétrica, criada por Thomas Edison em 1879. 
Como preceitua Barbosa (2003) a aplicação industrial exige que o invento seja a solução de um problema técnico, ou seja, pertinente a qualquer tipo de indústria. O outro elemento importante da noção é que o invento seja uma solução de um problema, de forma haja o propósito industrial, um problema técnico específico a ser resolvido, assim não basta somente a criação de objetos ou informações, resultantes de atividade humana, é preciso especificar qual o problema técnico a ser resolvido pela definição, sob pena de não ser patenteável.

Ademais, tais requisitos bases impostos por lei, direcionam para o entendimento pleno do que se pode ser tido como patente, de forma a orientar os interessados depositantes e filtrar aquelas criações que convenientemente se tornarão patenteáveis.

\section{O SISTEMA DE PATENTES NO BRASIL}

O Brasil, ao longo dos últimos anos, com o objetivo de cada vez mais não apenas estimular a inovação e por conseguinte melhorar sua competitividade no cenário mundial, como também se integralizar globalmente vem explorando alternativas que tornem o processo de obtenção de patentes mais célere, tais medidas beneficiam empresas, universidades e pesquisadores nacionais. É constante a função da proteção das patentes, como forma de incentivo não somente da inovação, como da proteção da mesma, nesse sentido:

A patente é uma unidade contraditória: protege o inventor, mas também o desafia ao facilitar a geração de novas invenções por terceiros, induzindo o seu próprio titular a prosseguir inventando para se manter à frente de seus competidores. Em outras palavras, a propriedade temporalmente limitada e o interesse público da informação divulgada - razão de ser público e privado da patente -é um instrumento de promoção do desenvolvimento tecnológico (MACEDO, 2000, p. 20).

Patentear uma criação não apenas trás o benefício da proteção legal como também à medida que novos inventos são divulgados permite que outros inventores desenvolvam suas próprias patentes, desta forma:

\footnotetext{
Em termos gerais, o sistema de patentes representa uma troca entre um ente o inventor e determinado poder concedente, onde o primeiro divulga a sua criação de fundo em troca de um período de exclusividade garantido pelo segundo. Trata-se de um conjunto de normas jurídicas que visam promover um determinado comportamento econômico para impulsionar o desenvolvimento - investimentos em pesquisa e na atividade econômica (CASCÃO, p. 17, 2009).
}

Sob essa perspectiva, o sistema de patentes, serve para proteger juridicamente, as 
pessoas físicas ou jurídicas, que por meio da sua criatividade trouxeram soluções para problemas pertinentes no setor do desenvolvimento tecnológico, garantindo assim o justo bônus àqueles que puseram seu investimento e tempo em prol do desenvolvimento da sociedade.

\subsection{Depósito de Patentes}

O Instituto Nacional da Propriedade Industrial - INPI, é a autarquia federal responsável, além de outras funções, pelas concessões das patentes. O caminho para evitar que uma criação seja utilizada, ou copiada, de forma indevida, começa pelo pedido de sua concessão e termina com sua aprovação, ou não.

A concessão da patente é um ato administrativo declarativo, ao se reconhecer o direito do titular, e atributivo (constitutivo), sendo necessário o requerimento da patente e o seu trâmite junto à administração pública. Ou seja, patente é um título de propriedade que confere ao seu titular o direito de impedir terceiros explorarem sua invenção, em um determinado território, por um limitado período de tempo, em troca da descrição da invenção (SUZIN, MARCANZONI e BITTENCOURT, p. 2, 2016).

Conforme dispõe a lei 9.279/96, tal concessão está subordinada à algumas etapas, que são realizadas pelo IMPI, sendo estas:

Art. 19. O pedido de patente, nas condições estabelecidas pelo INPI, conterá: I requerimento; II - relatório descritivo; III - reivindicações; IV - desenhos, se for o caso; $\mathrm{V}$ - resumo; e VI - comprovante do pagamento da retribuição relativa ao depósito (BRASIL, 1996)

Todos os procedimentos, deverão respeitar as normas e resoluções estabelecidas pelo INPI. Todos os pedidos de patentes deverão apresentar um título, que deverá ser conciso, claro e preciso, identificando o objeto do pedido, sem expressões ou palavras irrelevantes ou desnecessárias (SUZIN, MARCANZONI eBITTENCOURT, 2016).

De acordo com o INPI (Instituto Nacional da Propriedade Industrial), em seu Guia Básico de Patentes, primeiramente, o interessado em patentear uma invenção ou modelo de utilidade, deverá verificar se sua criação já foi patenteada por terceiros, ou seja, é importante verificar o referido pedido atenderá, ou não, aos requisitos de patenteabilidade, tal medida de pesquisa não é obrigatória, porém é aconselhável.

Cumprido o referido procedimento administrativo, o INPI expedirá a respectiva patente, tal instrumento é a única prova admissível pelo direito para demonstração da concessão do direito de exploração exclusiva da invenção ou do modelo de utilidade 
(COELHO, 2011).

\begin{abstract}
A patente tem prazo de duração determinado, sendo de 20 anos para a invenção e 15 para o modelo de utilidade, contados do depósito do pedido de patente (isto é, da data em que o pedido foi protocolado no INPI). Para garantir ao inventor pelo menos um tempo razoável de utilização da invenção ou modelo, contudo, o prazo de duração do direito industrial não poderá ser inferior a 10 anos, para as invenções, ou 7, para os modelos, contados da expedição da patente (COELHO, p. 109-110, 2011).
\end{abstract}

Assim, ao conseguir o registro da patente, o seu titular poderá por um período determiado de tempo, explorar de forma exclusiva sua patente e garantir eventuais lucros que essa Ihe trouxer, sem a possibilidade que sua invenção ou modelo de utilidade seja usado por que não tenha arcado também com o ônus do seu investimento.

\title{
3.2. Da Licença Compulsória
}

A propriedade industrial, e consequentemente as patentes, possuem para o direito um relevante interesse social, de forma que, uma vez concedida a patente, se o possuidor do direito de exploração não o utilizar de forma correta a fim de atender aos interesses sociais, tem-se a licença compulsória.

A licença compulsória trata das situações em que o titular da patente está obrigado a licenciar terceiros na exploração da invenção ou do modelo de utilidade correspondente. Isto porque, para o direito é considerado em alta estima o interesse social relacionado ao acesso às comodidades propiciadas pelo desenvolvimento industrial. Em outros termos, se o titular da patente de invenção ou modelo de utilidade não está exercendo o seu direito de forma a atender regular e convenientemente o mercado, outros empresários interessados e capacitados terão o direito de explorá-la, por meio da licença compulsória (COELHO, 2011).

Evidentemente, os licenciados remunerarão o dono da patente. Assim, se os direitos concedidos pelo INPI são exercidos de forma abusiva, ou se, por meio deles, se pratica abuso do poder econômico, caberá a licença compulsória. Também se impõe esta licença se o titular da patente, tendo já transcorridos 3 anos da sua expedição, não a explora por completo, ou se verifica o caso de insatisfatória comercialização (COELHO, p. 110, 2011).

Em suma tal licença compulsória ou como popularmente conhecida "quebra de patentes" é resultado do princípio que todos os tipos de propriedade devem seguir qual seja a função social. Uma vez concedida a patente é de vital importância que essa seja explorada de forma a agregar avanços para o meio tecnológico, o titular de uma patente não tem seus 
esforços findados na obtenção de seu registro, mas deve observar, durante o tempo que lhe foi oferecido como exclusivo explorador, a satisfação do seu uso para o mercado e evitar cometer abusos durante o exercício do seu direito.

\subsection{Da Ação de Nulidade}

A ação de nulidade se configura como um meio pelo qual a legislação permite que terceiros questionem a concessão de uma patente, tanto de forma judicial como também administrativa.

As patentes após concedidas podem ser invalidadas mediante a ação de nulidade em âmbito judicial. A lei brasileira prevê a possibilidade de qualquer pessoa com legítimo interesse ingressar com ação de nulidade questionando a validade de uma patente concedida a qualquer tempo de sua vigência. Os processos judiciais, porém, são geralmente custosos e lentos e enquanto não houver uma decisão definida o detentor da patente continuará usufruindo, na prática, dos direitos concedidos pela patente (SUZIN, MARCANZONI e BITTENCOURT, 2016). A lei 9.279/96, dispões em seu capítulo XI, seção III, acerca da ação de nulidade, prevê que:

Art. 173. A ação de nulidade poderá ser proposta pelo INPI ou por qualquer pessoa com legítimo interesse. Parágrafo único. O juiz poderá, nos autos da ação de nulidade, determinar liminarmente a suspensão dos efeitos do registro e do uso da marca, atendidos os requisitos processuais próprios (BRASIL, 1996).

Esse mecanismo surge proporcionar a garantia do contraditório e ampla defesa e demonstrar que o registro de patentes não é uma permissão absoluta, sendo possível o questionamento de suas irregularidades.

\section{DADOS E DESAFIOS DO SETOR DE PATENTES NO BRASIL}

O INPI (Instituto Nacional de Propriedade Intelectual) anualmente disponibiliza um relatório anual de suas atividades, no que diz respeito a todos os dados e panoramas à cerca de seu trabalho desempenhado durante todo o ano, além de trazer uma avaliação dos seus avanços e também do que ainda precisa ser alcançado.

Tomando como base o relatório do ano de 2018, este destaca que o Brasil é um país empreendedor, há em torno de 50 milhões de brasileiros desenvolvendo alguma atividade empresarial, de acordo com a Pesquisa Global Entrepreneurship Monitor (GEM). Isso significa 
PROPRIEDADE INTELECTUAL: UMA ANÁLISE ACERCA DO PROCESSO DE OBTENÇÃO DE PATENTES NO BRASIL

E-ISSN 2316-8080

que de cada 100 brasileiros adultos, com idade entre 18 e 64 anos em 2017, 36 deles estavam empreendendo.

O referido relatório, por uma lado admite que o Brasil ainda necessita de mudanças para corresponder às necessidades cada vez mais frenéticas do setor de concessão de patentes, entretanto, por outro lado, há uma melhora em tal quadro, sendo que de acordo com o relatório do ano de 2018 , houve um acréscimo de $25 \%$ no quadro funcional do INPI, com a contratação de 210 novos servidores para acelerar os exames dos pedidos de registros de marcas e patentes.

Apesar dos avanços, o Brasil aparece na lanterna do ranking global de inovação, de acordo com Buainain e Souza (2018), o Brasil ocupa a posição $69^{\circ}$ no Índice Global de Inovação, produzido pela Universidade de Cornell, Insead e Organização Mundial de Propriedade Intelectual (OMPI).

Outro dado que preocupa, pois mesmo sendo, a $8^{\mathrm{a}}$ economia do mundo, nenhuma empresa brasileira aparece na edição de 2018 no ranking das 50 Empresas mais inovadoras, desenvolvido pelo The Boston Consulting Group (BCG).

Ainda, de acordo com dados publicados pela Organização Mundial de Propriedade Intelectual (OMPI) no ano de 2018, o Brasil tem o pior desempenho entre os 76 principais escritórios do mundo responsáveis pelo registro de patentes e propriedade intelectual. Destaca a OMPI que, em média, a avaliação de uma solicitação de patente no INPI leva 95 meses para ser concluída.

Pontua Buainain e Souza (2018) que o atual quadro de baixo crescimento da economia e baixa taxa de inovação são resultados de um conjunto de fatores, entre os quais, é possível destacar o ambiente economicamente desfavorável, o que trás uma imprevisibilidade, fazendo com que haja uma atitude defensiva no que diz respeito a inovação. Destaca ainda, que no que diz respeito ao perfil de inovação das empresas indica-se que estas inovam mais no sentido de responder a problemas pontuais do que no sentido de ter uma posição mais ativa em busca de vantagens competitivas e inovações de produtos, sendo baixas as taxas que representam novidades para o mercado mundial.

Outros pontos destacados por Buainain e Souza (2018), que inibe o crescimento do setor de inovação no Brasil é alta burocracia, taxas de juros, custo elevado para importar, falta de infraestrutura, elevada complexidade do sistema tributário. Todos esses fatores fazem com que as iniciativas de inovação acabam por serem restringidas.

O relatório anual do ano de 2018 divulgado pelo INPI, destaca que no que diz respeito 
às patentes, no referido ano, a Diretoria de Patentes, Programas de Computador e Topografias de Circuitos Integrados (DIRPA) alcançou o índice de 55 decisões técnicas por examinador de patentes em produção plena, tal resultado se deve ao fato da consolidação de iniciativas de estímulo à produtividade, como o trabalho remoto, que atualmente contempla $30 \%$ do total de examinadores. Segundo o relatório a DIRPA realizou importantes ações visando otimizar o fluxo e controlar os seus processos, de forma a propiciar um aumento no número de decisões.

Ainda, no que diz respeito ao perfil dos depositantes, $42 \%$ dos depositantes de patentes de invenção se concentram em pessoas físicas, no que diz respeito às patentes de modelo de utilidade os números se ampliam, sendo as pessoas físicas responsáveis por $66 \%$ dos depositantes, de acordo com o relatório anual do ano de 2018 do INPI. Nessa perspectiva Buainain e Souza (2018) aduz que tal realidade se dá, entre outros motivos, pela maior segurança que a concessão da patente oferece a um particular:

Também é muito possível que, a despeito do recurso à análise antecipada por interesse confirmado do setor produtivo e possibilidade de negócio, os depositantes individuais sejam mais fortemente atingidos pela morosidade do sistema, uma vez que, não contando com a carta de patente, têm mais dificuldades para mobilizar parceiros e financiamento (BUAINAIN e SOUZA, p. 67, 2018).

Ainda, de acordo com o relatório anual de 2018 do INPI, é pertinente destacar que no que consta as patentes de inovação que as instituições de ensino e pesquisa, aparecem com o segundo maior índice de depositantes de patentes.

Tal protagonismo é bastante peculiar do sistema de inovação no Brasil, onde as empresas geralmente buscam apoio externo para assistir os esforços inovativos, também, por outro lado, reflete o esforço empregado pelas universidades e instituições de pesquisa para conscientizar da importância da gestão da propriedade intelectual, tal situação se materializa na crescente criação de núcleos de inovação tecnológica vinculados às instituições de pesquisa, isso revela que, por um lado, há o estímulo das instituições e por outro o nanismo das empresas no que diz respeito à inovação (BUAINAIN e SOUZA, 2018).

No mês de julho de 2019, o ministério da economia anunciou medidas para reduzir o número de pedidos de patentes a serem analisadas em $80 \%$ e reduzir para dois anos o prazo de espera para a concessão de uma patente pelo INPI. A mudança principal ocorrerá na análise dos pedidos de patente de invenção, nacionais ou estrangeiros, que já foram avaliados em outro país, que correspondem a $80 \%$ dos que estão na fila, de forma que, a partir de julho o INPI incorporou ao exame desses pedidos a busca de patentes realizada no exterior, tal medida visa aproveitar as análises feitas por outros países de forma a garantir mais celeridade 
no processo (AGÊNCIA BRASIL, 2019). De fato, o INPI já vem numa perspectiva de avanço no que concerne as patentes, resultado de uma série de medidas implementadas no organismo:

No período mais recente, a partir de 2014, o número de patentes concedidas praticamente duplicou, resultado de um grande esforço do INPI para reduzir o atraso acumulado, que envolveu a incorporação de novos examinadores de patentes, informatização, home office, melhoria de processos de análise, modernização tecnológica, convênios internacionais de troca de informação e principalmente a dedicação da equipe técnica comprometida com metas previamente acordadas (BUAINAIN e SOUZA, p. 14, 2018).

Em suma, nota-se que a concessão de patentes é um processo complexo, que para assegurar que os pedidos atendam aos requisitos previstos na lei, é necessário um exame técnico cuidadoso, apesar do Brasil ainda figurar com atraso em relação ao resto do mundo no que diz respeito a inovação, é possível notar, que há uma tendência notável a agilidade desse processo.

\section{CONSIDERAÇÕES FINAIS}

A propriedade intelectual possui um papel bastante significativo no desenvolvimento de um país, proporcionar um ambiente de incentivo a inovação entre as empresas e particulares, além de oferecer um respaldo jurídico para a sua proteção, é de fundamental importância para um crescimento sustentável.

As patentes ao proporcionar que inventores possam, durante um período tempo, ter exclusividade para explorar sua invenção, traduz a preocupação do direito em proteger os frutos do estudo e conhecimento, além dos investimentos das empresas para a criação de novos mecanismos.

Nesse contexto, o setor de patentes no Brasil, apesar de ainda enfrentar significativas dificuldades, estando em significativa desvantagem e atraso com relação a outros países, vem apresentando uma melhora significativa, dados mais recentes demonstraram um aumento no número de pedidos respondidos em relação a outros anos, resultado este gerado pela busca do INPI em potencializar e tornar o serviço mais célere, reconhecendo sua significativa importância para a economia e sociedade como um todo.

Notou-se, ademais, o destaque das instituições de ensino no que diz respeito a geração de patentes, o que demonstra o significativo incentivo à produção científica nesses 
ambientes.

Por outro lado, nota-se que no que diz respeito as empresas ainda há uma situação pouco significativa no que diz tange a atividade inovadora, tal quadro demonstra a existência de fatores que inibem tal progresso nessa área.

É certo que, o sistema de patentes é um mecanismo indispensável para o crescimento da economia e, por conseguinte da sociedade, devendo ser incentivada e protegida pela legislação vigente.

\section{REFERÊNCIAS BIBLIOGRÁFICAS}

BARBOSA, Denis Borges, Uma Introdução à Propriedade Intelectual. $2^{\mathrm{a}}$ Edição. Rio de Janeiro: Editora Lúmen Júris, 2003.

BRASIL. Constituição da República Federativa do Brasil. Disponível em: http://www.planalto.gov.br/ccivil_03/constituicao/constituicao.htm.Acesso em agosto de 2019.

BITTENCOURT, Rafael Sortica, SUZIN, Querli Polo, MARCANZONI, Ana Paula Mansan. Registros de Patentes no Brasil com Foco nas Patentes Verdes. In XVI Mostra de Iniciação Científica, Pós-Graduação, Pesquisa e Extensão. Universidade Caxias do Sul. Rio Grande do Sul: 2016. Disponível em: http://www.ucs.br/etc/conferencias/index.php/mostraucsppga/xvimostrappga/paper/ viewFile/4844/1718 Acesso em: setembro de 2019.

BUAINAIN, Antônio Márcio e SOUZA, Fraga Roney. Propriedade intelectual, inovação e desenvolvimento: desafios para o Brasil. Rio de Janeiro: ABPI; 2018.

CASCÃO. Luís Bernardo Coelho. O Prazo de Validade Das Patentes Pipeline: Remanescente de Proteção da Patente Originária e Limitador. Dissertação (Mestrado em Direito) - Universidade Candido Mendes. Rio de Janeiro: 2009.

CHAVES, M. P. S. R.; NOGUEIRA, M. G. Propriedade intelectual, globalização e desenvolvimento: Uma reflexão sobre os caminhos para o desenvolvimento sustentável da Amazônia. Desenvolvimento e Meio Ambiente, n. 18, p. 115-128, jul./dez. 2008. Editora UFPR

COELHO, Fábio Ulhoa. Manual de direito comercial: direito de empresa. $23^{a}$ Edição. São Paulo: Saraiva, 2011.

DURÃES, Valéria Ferro. Propriedade Intelectual: Direito Industrial e Direito Autoral.Disponível em https://www.meuadvogado.com.br/entenda/propriedadeintelectual-direito-industrial-edireioautoral.html Acesso em setembro de 2019.

FAZZIO Júnior, Waldo. Manual de Direito Comercial. $17^{a}$ Edição. São Paulo: Editora Atlas, 
PROPRIEDADE INTELECTUAL: UMA ANÁLISE ACERCA DO PROCESSO DE OBTENÇÃO DE PATENTES NO BRASIL

2016.

INPI, Instituto Nacional da Propriedade Industrial. Vários acessos. Disponível em www.inpi.gov.br, 2019.

Lei 9279, de 14 de maio. De 1996. Disponível em:

http://www.planalto .gov.br/ccivil_03/leis//9279.htm Acesso em setembro de 2019.

Lei 9610, de 19 de fevereiro. De 1998. Disponível em: http://www.planalto.gov.br/ccivil_03/leis//9610.htm Acesso em setembro de 2019.

LEMOS, Ronaldo. Direito de Propriedade Intelectual. Rio de Janeiro: Editora FGV, 2011.

MACEDO, Maria Fernanda. Patentes, pesquisa \& desenvolvimento: um manual de propriedade industrial. Rio de Janeiro: Fiocruz, 2000.

MAMEDE, Gladson. Direito Empresarial Brasileiro: empresa e atuação empresarial, volume 1. $8^{\text {a }}$ Edição: São Paulo. Atlas, 2015.

NEGRÃO, Ricardo. Manual de Direito Comercial de Empresa, $12^{\mathrm{a}}$ Edição: São Paulo: Saraiva, 2015.

TEXEIRA, Francisco. Tudo o que você queria saber sobre patentes e tinha vergonha de perguntar. Editora Clever: São Paulo, 2006.

VERDÉLIO, Andreia. Governo anuncia plano para acelerar análise de pedidos de patentes. Agência Brasil, 2019. Disponível em

http://agenciabrasil.ebc.com.br/economia/noticia/2019-07/governo-anuncia planopara-acelerar-analise-de-pedidos-de-patentes Acesso em novembro de 2019. 